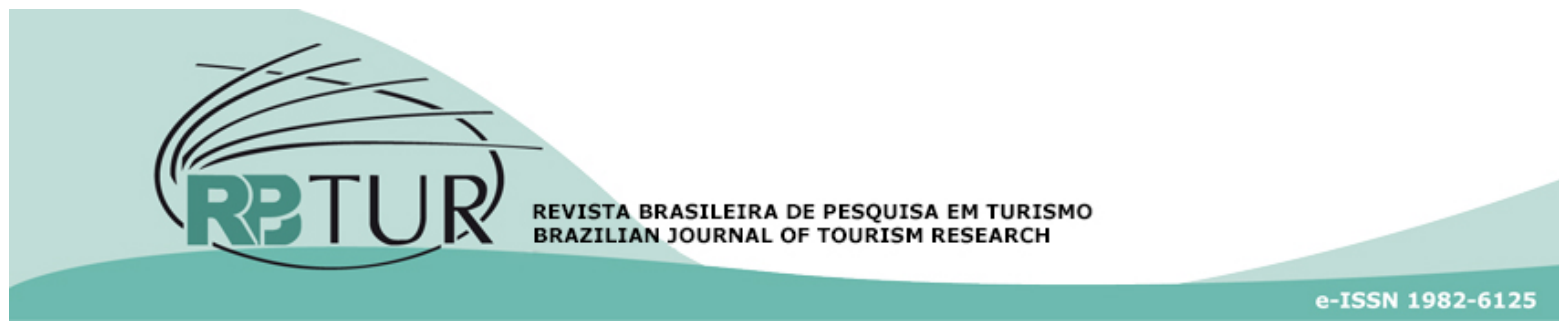

\title{
Artigos
}

\section{Comunicação on-line e off-line para marca-país: um estudo exploratório sobre a Marca Brasil}

\author{
Online and offline communication for country-brands: an exploratory \\ study of the Brazil Brand
}

\section{Comunicación on-line e off-line para marca país: un estudio exploratorio sobre la Marca Brasil}

Flávio Notomi Kanazawa1; Janaina de Moura Engracia Giraldi1; Jorge Henrique Caldeira de Oliveira1

1 Universidade de São Paulo (USP), São Paulo, SP, Brazil.

$\begin{array}{ll} & \text { Resumo } \\ & \text { A acirrada competição internacional entre destinos turísticos força seus gestores a oferecer a } \\ \text { Palavras-chave } & \text { seus públicos propostas de valor únicas, buscando melhorar suas imagens e destacando seus } \\ \text { diferenciais e experiências turísticas exclusivas. Nesse processo, a adequada gestão e comu- } & \text { nicação de uma marca-país se torna ainda mais relevante. O número cada vez maior de pes- } \\ \text { Comunicação on-line e off-line. } & \text { soas que utilizam a internet para planejar suas viagens gera nos gestores de marcas-país a } \\ \text { Marca Brasil. } & \text { preocupação de construir uma sólida atuação digital para suas marcas. Diante desse cenário, } \\ \text { Visit Brasil. } & \text { este artigo buscou compreender as práticas de gestão e comunicação desenvolvidas para a } \\ \text { Embratur. } & \text { Marca Brasil e sua forma de atuação na internet. Para tal, foi feita uma pesquisa qualitativa e } \\ & \text { exploratória que realizou entrevis-tas em profundidade conduzidas de forma semiestruturada } \\ & \text { com os profissionais da Embratur responsáveis pela gestão da Marca Brasil e sua atuação } \\ & \text { online. Os resultados deste artigo descrevem os objetivos centrais da marca, suas aplicações } \\ & \text { e atividades desenvolvidas para atingi-los, dando ênfase às suas atuações através do website } \\ & \text { Visit Brasil e suas páginas em mídias sociais. }\end{array}$

\section{Abstract}

Keywords::

Online and offline communication Brazil Brand.

Visit Brazil.

Embratur.
The fierce international competition among tourist destinations forces their managers to offer their public unique value propositions, seeking to improve their images and highlighting their unique tourist experiences and advantages. In this process, the proper management and communication of a country-brand becomes even more relevant. The growing number of people who use the Internet to plan their trips causes country-brand managers to be concerned with building a solid digital performance for their brands. Given this scenario, this article seeked to understand the management and communication practices developed for the Marca Brasil (Brazil Brand) and its way of acting on the Internet. To this end, a qualitative and exploratory research was carried out that conducted in-depth interviews in a semi-structured manner with the Embratur professionals responsible for the management of the Brazil Brand and its online performance. The results of this article describe the core objectives of the brand, its applications and the activities developed to achieve them, emphasizing their actions through the Visit Brazil website and its social media pages.

Resumen

La feroz disputa internacional entre los destinos turísticos obliga a sus gerentes a ofrecer a su público propuestas de valor únicas, tratando de mejorar su imagen y destacando sus diferencias y experiencias turísticas exclusivas. En este processo, la correcta administración y comunicación de una marca país és aún más importante. El número cada vez mayor de personas
Comunicación on-line y off-line. Marca Brasil. 
Visit Brasil.

Embratur.

Avaliado por pares.

Recebido em: 25/06/2018.

Aprovado em: 28/08/2018. que utilizan la internet para planear viajes preocupa los gerentes de la marca país a construir una sólida presencia digital para sus marcas. En ese panorama, este estudio anheló entender las actividades de administración y comunicación aplicadas a la Marca Brasil y su presencia digital. Para eso, fue utilizado el método qualitativo y exploratorio que realizó una entrevista con los gerentes de la Marca Brasil y sus actividades online. Los resultados de este estudio describen los objetivos principales de la marca, sus aplicaciones y las actividades realizadas para alcanzarlos, enfatizando sus actividades por medio del website Visit Brasil y sus páginas en medios sociales.

Como citar: Kanazawa, F. N.; Giraldi, J. M. E.; Oliveira, J. H. C. (2019). Comunicação on-line e off-line para marca-país: um estudo exploratório sobre a Marca Brasil. Revista Brasileira de Pesquisa em Turismo, São Paulo, 13 (1), p. 58-71, jan./abr. http://dx.doi.org/10.7784/rbtur.v13i1.1472

\section{INTRODUÇÃO}

Diante da popularização da internet, desenvolvimento de novas tecnologias e ação de forças contemporâneas que potencializam os efeitos do processo de globalização, observa-se nas últimas décadas um grande crescimento no fluxo de pessoas entre os países, do comércio exterior e das transações financeiras internacionais. 0 crescimento do setor de turismo tem superado indicadores do crescimento econômico mundial nos últimos anos: por exemplo, em 2017, o turismo mundial teve um crescimento de 7\% (OMT, 2018) ao passo que o crescimento da economia global foi de 3,1\% (The World Bank, 2018). No Brasil, o setor de turismo representou em 2016 cerca de 7 bilhões de empregos no Brasil (7,8\% do total de postos no país), com projeção de crescimento para 2027 para 8,6\% do total. O setor também foi responsável por 8,5\% do PIB do país em 2016, com projeção de crescimento para 9,1\% em 2027 (WTTC, 2017).

Como efeito desse cenário, a competição entre os países por investimentos, turistas e mercados consumidores para a exportação de produtos se torna cada vez mais acirrada (Fetscherin, 2010; Hynes, Caemmerer, Martin, \& Masters, 2014; Stock, 2009). Frente a esse quadro, diversos países passam a utilizar estratégias de gestão de marca e comunicação em busca de diferenciação nessa disputa global, tornando evidente, dessa forma, que não apenas empresas, mas também países buscam hoje destaque e reconhecimento no contexto mundial (Fan, 2006, 2010; Fetscherin, 2010).

A literatura destaca a importância que um país desenvolva uma boa imagem junto aos públicos estrangeiros, uma vez que a mesma é capaz de influenciar positiva ou negativamente decisões como a aquisição de seus produtos, a realização de investimentos e a intenção de visitá-lo (Diamantopoulos, Schlegelmilch, \& Palihawadana, 2011; Hynes et al., 2014; Nebenzahl, 2007).

Especificamente sobre o turismo, Hakala, Lemmetyinen e Kantola (2013) afirmam que a imagem de um país influencia fortemente o processo decisório de escolha de destinos turísticos, uma vez que potenciais turistas geralmente possuem conhecimentos limitados acerca de lugares que ainda não visitaram e suas decisões podem ser afetadas por estereótipos. Dessa forma, os autores discorrem a respeito da importância de, a partir de iniciativa do próprio país ou de empresas promotoras de turismo, fornecer informações de qualidade e na quantidade certa para melhorar a imagem do país e, no fim das contas, convencer potenciais turistas a visitá-lo.

Nesse processo, a internet assume papel fundamental, uma vez que vem gerando grandes mudanças na maneira de buscar e obter informações sobre turismo e dos produtos e serviços vinculados ao turismo. Ao longo dos anos a internet se tornou uma das principais fontes de informações turísticas utilizadas pelos indivíduos (Morrison, 2012). Assim, é primordial que os gestores de marcas-país deem atenção para esta fonte na gestão e na comunicação de marca, de modo que, ao utilizarem as ferramentas oferecidas dentro deste ambiente (como a criação de websites, aplicativos de celular e páginas em mídias sociais), consigam influenciar positivamente as decisões de potenciais turistas de visitarem o país, satisfazendo suas necessidades de informações (Farias, Aguiar, Kovacs, \& Andrade, 2011). 
Além disso, as características interativas e colaborativas da internet permitem que as pessoas busquem e compartilhem conteúdos sobre seus interesses de modo bastante prático, dando a elas o poder de expressar suas opiniões, conhecimentos e experiências sobre qualquer assunto (Adamson, 2008). Abre-se também a oportunidade para que as organizações participem desse espaço, de forma a conhecer profundamente seus públicos para melhor satisfazer suas necessidades, além de criar e disseminar conteúdos para aproximá-los em torno da marca e influenciar suas decisões (Rowles, 2014).

Trazendo a presente discussão à realidade brasileira, destaca-se que o Instituto Brasileiro de Turismo (Embratur) lançou, em 2005, uma marca-país nacional, a Marca Brasil, fazendo parte do Plano Aquarela - Marketing Turístico Internacional do Brasil. Tal planejamento coloca em prática diversas ações para fortalecer a imagem do país a fim de torná-lo um potencial destino turístico no exterior (Castro \& Giraldi, 2012). Entretanto, a forma de atuação dessa iniciativa na internet, bem como suas finalidades e práticas desenvolvidas em prol dos objetivos da Marca Brasil são assuntos que permanecem pouco abordados pela literatura atual.

Diante dessa constatação e sabendo da grande importância da internet para o cenário turístico internacional como um todo e mais especificamente para o fortalecimento dos destinos turísticos brasileiros no exterior, é muito importante entender de que forma o Brasil, através de suas iniciativas governamentais, atua utilizando as ferramentas disponibilizadas pela internet para atrair turistas estrangeiros a visitar o país e suprir suas necessidades de informação ao planejar uma viagem ao Brasil.

Assim, o objetivo deste artigo é compreender as práticas de gestão e comunicação desenvolvidas para a Marca Brasil, em específico as formas de atuação na internet. Para alcançá-lo, realizou-se pesquisa qualitativa e exploratória, por meio de entrevistas em profundidade conduzida de forma semiestruturada com os profissionais da Embratur responsáveis tanto pelas atividades de comunicação e marketing da Marca Brasil como pela criação e gerenciamento de seus conteúdos exclusivos para a internet.

O presente estudo encontra-se dividido nas seguintes partes: após esta introdução, é apresentado um referencial teórico sobre imagem de país, imagem de destinos turístico e marca-país, com ênfase na Marca Brasil, além de conceitos relacionados ao tema de comunicação digital. Na sequência, é apresentada a descrição do método de pesquisa utilizado. Por último, apresentam-se os resultados e considerações finais, que retomam o objetivo deste estudo e trazem suas limitações e contribuições à literatura.

\section{REFERENCIAL TEÓRICO}

\subsection{Imagem de país, imagem de destino turístico e marca-país}

Nebenzahl (2007) afirma que todos os países possuem uma imagem, seja ela positiva ou negativa. 0 conceito de imagem de país é definido como uma impressão geral que os consumidores possuem a respeito de determinado país, a qual é formada a partir de conhecimentos e experiências prévias relacionados a ele, sendo afetada também por informações (equivocadas ou verdadeiras) a respeito de sua população e condições socioeconômicas e políticas (Hakala, \& Lemmetyinen, 2011; Hynes et al., 2014).

Kotler e Gertner (2004) complementam dizendo que a imagem de um país é formada por crenças e informações (muitas vezes desatualizadas e exageradas) relacionadas a ele, incluindo aspectos como geografia, cultura, arte, história e celebridades. Estas crenças e informações frequentemente resultam em simplificações e generalizações excessivas que nem sempre são factuais, além de gerar estereótipos (positivos ou negativos) sobre o país. A literatura apresenta também que a imagem que se tem de um país pode servir como um atalho para o processamento de informações na mente das pessoas, sendo capaz de influenciar as decisões de compra de produtos oriundos de determinado país, a intenção de visitá-lo e a realização de investimentos nesse local (Fetscherin, 2010; Kotler \& Gertner, 2004; Nebenzahl, 2007).

Nadeau, Heslop, O’Reilly e Luk (2008) afirmam existir uma distinção conceitual entre imagem de país e imagem de destino turístico. A primeira é mais abrangente, englobando o país como um todo e com foco majoritariamente nas percepções a respeito da aquisição de produtos cuja fabricação esteja relacionada a esse país. Já a segunda foca nas impressões sobre determinada localidade (podendo ser um país, estado, região ou cidade) e nas intenções de visitá-la, de modo que, como complementam Chen e Tsai (2007), a 
imagem de um destino turístico, além de influenciar o processo de escolha de destino turístico pelos indivíduos, afeta seu comportamento pós-compra, abrangendo a intenção de retornar a ele e de indicá-lo a outras pessoas.

Diante da acirrada disputa global por investimentos, negócios, turistas e exportações, e sabendo que a imagem que se tem de um país pode influenciar o resultado dessa competição, muitos países passaram a adotar estratégias de gestão de marca e comunicação para se diferenciarem de seus concorrentes. Surge assim o conceito de marca-país, que aborda o uso de conceitos, estratégias e práticas de gestão de marcas em prol da melhoria da imagem de um país (Fan, 2006, 2010).

0 gerenciamento de uma marca-país consiste na criação de associações positivas para esta marca, para seus produtos, habitantes e suas localidades (Florek, 2005). Fetscherin (2010) destaca que uma marcapaís compreende diversos níveis, componentes e assuntos. Por pertencer ao domínio público, suas ações devem abranger todas as partes envolvidas, pois afeta diferentes elementos da imagem do país, como sociais, econômicos, políticos, culturais, históricos, ambientais etc. Por meio de seu gerenciamento almeja-se melhorar as avaliações internacionais a respeito do país, além dos objetivos já citados, como estímulo às exportações e atração de investimentos, negócios e turistas.

Anholt (2005), no que tange ao gerenciamento de marca-país, propõe um modelo que reúne as seis categorias de comunicação utilizadas pelos países para se expressarem e se promoverem junto a seus públicos. A correta gestão de marca-país alinha a maior quantidade possível destas categorias na comunicação e na realização da estratégia definida; se bem operacionalizada, tal estratégia é capaz de melhorar tanto a confiança interna como o desempenho externo do país.

As seis categorias são: turismo (geralmente o aspecto mais visível e mais trabalhado na gestão de marcapaís); marcas exportadas (formam uma das maneiras mais potentes para criar e sustentar uma imagem forte a respeito do país); políticas externas e domésticas (o comportamento político, os países com os quais se relaciona e seus líderes são avaliados pelos estrangeiros e suas atividades devem estar em sintonia com as demais categorias de comunicação); investimentos e imigração (envolve os esforços do país para atrair talentos, investimentos e negócios); cultura, patrimônio histórico e esportes (promovem riqueza, dignidade, confiança e respeito ao país no exterior); e pessoas (envolve diplomatas, políticos, celebridades, a maneira como seus habitantes se comportam no exterior e o tratamento dado por eles a estrangeiros). Estas categorias devem ser gerenciadas em sinergia, inclusive com gestão diplomática e outras políticas públicas integradas (Anholt, 2005).

Se no passado a gestão de uma marca-país era característica de países desenvolvidos, hoje países em desenvolvimento também dedicam esforços e recursos para criar uma imagem de si mais atrativa e positiva, de modo que esta é uma tarefa inadiável para reduzir suas disparidades frente aos países desenvolvidos (Herstein, 2011).

No atual panorama mundial do turismo, a grande competição entre os diversos destinos turísticos faz com que os mesmos não mais se diferenciem pela qualidade de suas acomodações e belezas locais. Diante disso, tornou-se necessário que cada destino busque se distinguir dos demais oferecendo e comunicando uma proposta de valor original, destacando suas características culturais, seus diferenciais e experiências únicas, que só podem ser ali vivenciadas (Campelo, Aitken, Thyne, \& Gnoth, 2014).

Nesse cenário, a internet se tornou um elemento primordial para que essas informações comunicadas pelos países sejam rapidamente e facilmente recebidas por seus públicos-alvo. Assim, os conteúdos desenvolvidos para a promoção de destinos turísticos e disponibilizados na internet devem ser criados a fim de atrair turistas ao destino promovido e suprir as necessidades de informações turísticas dos usuários, tirando proveito de todas as potencialidades do ambiente online (Farias et al., 2011; Fernández-Cavia, Rovira, Díaz-Luque, \& Cavaller, 2014).

\subsection{Marca Brasil}

Trazendo essa discussão para a realidade brasileira, a Embratur criou em 2005 a Marca Brasil por meio do Plano Aquarela - Marketing Turístico Internacional do Brasil, o qual foi desenvolvido em três etapas: (1) 
diagnóstico da situação do turismo brasileiro no contexto mundial; (2) criação de planejamento estratégico, que definiu uma visão de futuro para o setor, as estratégias adotadas e seus objetivos; (3) e a elaboração de um plano operacional, que definiu as ações, ferramentas e programas colocados em prática para atingir os objetivos propostos (Ministério do Turismo, 2009).

Apesar dos diferentes benefícios que podem ser gerados a partir da adequada gestão de uma marca-país, Khauaja e Hemzo (2007) criticam o fato de a Marca Brasil atuar como foco majoritário no turismo, limitando ou colocando em segundo plano a atuação que a marca pode ter para incentivar a exportação dos produtos brasileiros.

Ao analisar o desenvolvimento e a gestão da Marca Brasil, Castro e Giraldi (2012) apontam algumas falhas nesse processo: ausência de análise das principais ameaças e oportunidades ao Brasil no cenário turístico internacional; não utilização de celebridades na formação da base estratégica da marca; não foram destinados recursos financeiros especificamente para o gerenciamento da marca; falta de controle das exportações dos produtos que utilizam a Marca Brasil no exterior; problemas na comunicação da marca à população local; carências na diferenciação da Marca Brasil frente às demais, uma vez que elementos artísticos, históricos e arquitetônicos do país foram deixados em segundo plano. Como sugestões à marca para o futuro, os autores destacam: investimentos em infraestrutura turística, comunicação, treinamento e segurança; realização de estudos que antecipem possíveis ameaças ao país, abrangendo aspectos políticos, sociais, econômicos e ambientais internos e externos; utilização de personalidades mundialmente conhecidas e que transmitam credibilidade, auxiliando na tarefa de persuadir potenciais turistas a visitarem o Brasil; destinação de recursos específicos para o gerenciamento da marca; controle da imagem que empresas exportadoras transmitem a respeito da Marca Brasil no exterior; promoção da marca de modo mais intenso dentro do território brasileiro; e melhor exploração dos elementos da arte, história e arquitetura brasileira em prol da Marca Brasil.

Mariutti e Giraldi (2011) afirmam que o posicionamento da Marca Brasil, em harmonia com as empresas do setor de turismo, exerce o papel de referência estratégica para dimensionar a marca como oferta de destinos turísticos, expondo a totalidade de sua identidade de modo que os potenciais turistas a reconheçam e a valorizem, diferenciando-a das demais. Além disso, cientes do fato de cada vez mais pessoas utilizarem a internet para planejar suas viagens, sugerem que a Marca Brasil deve acompanhar as inovações da internet, das mídias sociais e demais ferramentas, de modo que as estratégias de construção e gerenciamento da marca sejam contínuas e duradouras, dando destaque para a padronização e o controle do uso da marca no ambiente online.

\subsection{Comunicação de destinos turísticos através de ferramentas digitais}

A era do marketing online gera profundas mudanças na maneira como os turistas obtêm informações sobre turismo e serviços de hospitalidade, fato que impulsionou nos últimos anos o desenvolvimento de websites que visam suprir as necessidades de informação dos turistas que utilizam a internet para planejar suas viagens (Farias et al., 2011; Morrison, 2012).

Mais do que isso, uma experiência de navegação positiva em conteúdos turísticos na internet, ao auxiliar na formação de conhecimento das atrações e experiências turísticas que podem ser realizadas em determinado destino, expondo uma identidade bem definida da localidade divulgada, é capaz de impressões positivas e atrativas sobre ela e de influenciar os indivíduos na formação da imagem de um destino turístico e na intenção de visitá-lo (Carvalho et al., 2016; Farias et al., 2011).

Nesse contexto, a Embratur enxerga as seguintes vantagens da utilização de ferramentas de comunicação digital na divulgação da Marca Brasil: elevado alcance geográfico; alto número de pessoas que terão acesso às informações; agilidade na disponibilização e acesso; boa relação custo-benefício devido ao alto impacto causado; interatividade com o público; e capacidade de mensuração dos resultados proporcionada por tais ferramentas. O website Visit Brasil consiste num importante pilar no trabalho de promover os destinos turísticos e os produtos brasileiros a milhões de turistas em todo o mundo, fornecendo aos potenciais turistas informações a respeito das experiências que podem ser vividas no país, além de dicas práticas de viagem e 
informações sobre os destinos brasileiros. Além disso, visando suprir a necessidade de informação da imprensa e de profissionais do turismo, este website divulga notícias, relatórios, estudos de mercado e materiais de apoio à divulgação dos destinos turísticos brasileiros (Brasil, 2014).

\section{MÉTODO}

Para atingir o objetivo deste artigo, foi realizada uma pesquisa qualitativa e exploratória, esta última recomendada quando existe pouco conhecimento sobre o tema abordado, desejando-se gerar maior familiaridade e proximidade com o assunto e promover o aprimoramento de ideias ou a descoberta de intuições (Raupp \& Beuren, 2003). A realização de pesquisa qualitativa foi voltada a descobrir achados e reações não antecipados sobre o problema de pesquisa e aproximar o pesquisador do problema (HAIR et al., 2014). Tal escolha é justificada também pelo fato de que a novidade do tema estudado e a carência de trabalhos relacionados a ele impossibilitam a utilização de métodos plenamente estruturados para a coleta dos dados (Malhotra, 2012).

Foram realizadas entrevistas em profundidade conduzidas de forma semiestruturada com profissionais e gestores da Marca Brasil na Embratur, e nela foram discutidas as diretrizes para a criação e gerenciamento da Marca Brasil e as ações realizadas especificamente para a atuação da marca na internet. As entrevistas foram realizadas no prédio da Embratur em Brasília/DF em novembro de 2015. Estiveram presentes o Coordenador-Geral de Publicidade e Propaganda da organização (responsável tanto pelas atividades da marca tanto no meio online como no off-line) e outras duas profissionais. Esta equipe de três pessoas é responsável pela atuação da Marca Brasil na internet, portanto foram entrevistados todos os funcionários da Embratur que poderiam contribuir para o atingimento dos resultados desta pesquisa. A sugestão de data e tempo de duração da entrevista foi realizada pelos próprios entrevistados, de acordo com a disponibilidade de suas agendas de compromissos.

A entrevista foi conduzida por um único pesquisador que não possuía nenhuma relação prévia com a Embratur, e foi agendada em uma troca de e-mails com uma das entrevistadas. 0 endereço de e-mail desta profissional foi obtido pelo website da Embratur, e o contato foi iniciado com o envio de uma solicitação de realização de entrevista junto com uma carta de apresentação do pesquisador.

0 roteiro de entrevista foi desenvolvido a partir de temas constatações destacados por outros autores em seus trabalhos sobre comunicação digital voltada para turismo e gerenciamento de marca-país. Para exemplificar, foram abordados durante a entrevista como a Embratur atua para: gerenciar as diferentes categorias propostas no modelo hexagonal de Anholt (2005) citadas anteriormente; diferenciar os destinos turísticos brasileiros dos demais e comunicar uma proposta de valor original para o país (Campelo, Aitken, Thyne, \& Gnoth, 2014); gerar conteúdos na internet para suprir as necessidades de informações turísticas dos indivíduos e convencê-los a visitar o Brasil (Farias et al., 2011; Fernández-Cavia, Rovira, Díaz-Luque, \& Cavaller, 2014); superar as falhas na gestão da marca destacadas por Castro e Giraldi (2012); etc.

Os dados qualitativos coletados foram analisados seguindo as orientações de Bardin (2011), que divide a análise de conteúdo em três momentos: pré-análise; exploração do material; e tratamento dos resultados, inferência e interpretação. A análise qualitativa permite que os dados sejam analisados à medida que são coletados de modo iterativo, possibilitando modificações e adaptações nas questões em busca de análises mais aprofundadas (Hair, Celsi, Ortinau, \& Bush, 2014). Os dados coletados a partir das respostas das entrevistas foram transcritos e analisados conjuntamente com as notas de campo criadas durante as entrevistas.

\section{APRESENTAÇÃO E DISCUSSÃO DOS RESULTADOS}

\subsection{Comunicação e gestão da Marca Brasil}

A apresentação dos resultados se inicia abordando as finalidades da Marca Brasil definidas pela Embratur. Embora a marca-país brasileira tenha sido utilizada no passado pela Agência Brasileira de Promoção de Exportações e Investimentos (APEX) para a divulgação de produtos de exportação como cachaça, água de 
coco e guaraná, a Marca Brasil é utilizada atualmente exclusivamente em prol do turismo, informação em sintonia com a colocação de Khauaja e Hemzo (2007) abordada anteriormente.

Segundo os entrevistados, as atividades relacionadas à Marca Brasil atuam em frentes distintas, abrangendo três áreas dentro da Embratur: a diretoria de marketing, responsável pelas atividades de relações públicas, publicidade e propaganda e comunicação digital; a diretoria de produtos e destinos, responsável pela estruturação dos produtos que serão divulgados pela Embratur no exterior, participação e realização de feiras (importante ponto de contato da Embratur com o trade turístico, um de seus principais públicos, formado por agências de turismo, empresas de transporte, hospedagem e relacionadas a atividades turísticas de cada destino, centros de eventos, entre outros) e captação de eventos (viabilizar a realização de grandes eventos no Brasil com repercussão internacional); e a diretoria de mercados internacionais, responsável pelo relacionamento da Embratur com o trade turístico nos mercados internacionais.

O fato de o Brasil ser um país de enormes dimensões, no qual existem diferentes atividades econômicas, características geográficas, atrativos turísticos e diferenças culturais entre suas regiões torna a promoção no exterior das atividades turísticas brasileiras tarefa bastante desafiadora. Para os gestores da marca, o fato de o Brasil englobar características turísticas tão variadas (como sol e praia, ecoturismo, turismo de aventura, turismo cultural, turismo de negócios etc.) faz com que trabalhar e promover essa diversidade se torne imprescindivel, conforme explica um entrevistado:

\begin{abstract}
Temos a Diretoria de Produtos que elenca quais são os principais produtos a se trabalhar, e promovemos cada um deles dependendo da oportunidade. Por exemplo: participamos de feiras exclusivas para turismo de negócio e incentivos, nas quais buscamos promover o turismo de negócio. Ou seja, participamos de feiras específicas para promover determinado segmento. Para a cultura, buscamos identificar oportunidades para promover a cultura brasileira, como festivais de cinema, e recentemente realizamos a promoção do Rock in Rio, e assim por diante. Utilizamos os grandes eventos e procuramos oportunidades para promover segmentos e nichos específicos.
\end{abstract}

Em sintonia a Campelo et al. (2014), a Embratur reconhece que a grande competição internacional entre os destinos turísticos força cada um deles a oferecer propostas de valor únicas, e para tal busca comunicar a diversidade brasileira, além dos diferenciais e experiências exclusivas do país. Para promover essa diversidade, a Embratur comunica os diferentes atrativos brasileiros, de acordo com as oportunidades de divulgação que surgem e realizando um diagnóstico do melhor produto a ser promovido em determinado momento, ocasião ou local. Por exemplo: a promoção do turismo de negócios costuma ser feita em feiras exclusivas para esse segmento; o turismo cultural é divulgado em eventos como festivais de cinema e espetáculos musicais.

Estratégia semelhante é utilizada na atuação da marca na internet, já que são publicados diariamente conteúdos gerais (disponibilizados para o mundo inteiro) e também conteúdos segmentados (exclusivos a determinado país, continente ou região), de modo a comunicar os melhores produtos turísticos brasileiros para cada localidade, de acordo com um diagnóstico prévio realizado pela organização.

Sabe-se que a população local tem papel fundamental para o sucesso de uma marca-país (Anholt, 2005; Fetscherin, 2010). Diante disso, a Embratur destaca a grande importância dos brasileiros no processo de consolidação do país como um destino turístico de sucesso, notadamente sua alegria e hospitalidade com os estrangeiros. Esse fato foi comprovado através de pesquisas realizadas após a Copa do Mundo de 2014, que mostraram que o aspecto que mais surpreendeu aqueles que vieram ao país para o evento foi a receptividade da população local. Assim, o povo brasileiro vem ganhando cada vez mais relevância nas campanhas de comunicação da Embratur voltadas ao público estrangeiro.

Como abordado anteriormente, a gestão de uma marca-país deve criar esforços para melhorar a imagem do país no exterior a fim de atrair um maior número de turistas, além dos benefícios para a atração de investimentos e estímulo às exportações (Diamantopoulos et al., 2011; Hynes et al., 2014; Nebenzahl, 2007).

A partir das entrevistas, entende-se que a Embratur define que a imagem que deseja que os estrangeiros tenham sobre o Brasil é a de um país diverso, com cultura marcante e com um povo muito acolhedor e receptivo, aspectos fortemente promovidos nos trabalhos de comunicação da marca. Além disso, também são lembrados os clichês a respeito do Brasil, sendo considerados importante trabalhá-los e impossível deixá-los de lado. Exemplo disso é o turismo de sol e praia no Brasil, atividade com fama mundial, de fato baseada em uma grande riqueza natural do país nesse aspecto. 
Por outro lado, há também clichês que a Embratur procura combater, sendo que seu principal exemplo é a não exposição da figura sensual feminina em suas campanhas. Esse é um grande estereótipo que o Brasil possui no exterior, e há uma preocupação da organização de trabalhar a figura feminina em seus materiais promocionais apenas em um contexto familiar e maternal, e não sensual, de modo a dissociar o Brasil da prática de turismo sexual.

Aplicando o modelo de gerenciamento de marca-país de Anholt (2005) à Marca Brasil, nota-se que o foco principal do país está na categoria turismo, sendo que em muitas de suas ações os componentes da categoria de cultura, patrimônio histórico e esportes são explorados como atrativos turísticos, enquanto que o vértice de marcas exportadas não mais faz parte de suas atividades. Além disso, foi evidenciado que: a categoria de pessoas, no caso brasileiro, possui um papel fundamental na avaliação dada ao Brasil pelos turistas estrangeiros que visitam o país, os quais se surpreendem positivamente a respeito do bom tratamento dado a eles pela população local; a Embratur, sendo um órgão público, é responsável por traduzir para as atividades ligadas ao turismo as políticas governamentais definidas para o setor; e, no que tange à categoria de investimentos e imigração, o Brasil concentra seus esforços no sentido de atrair a realização de eventos de repercussão mundial no país.

Castro e Giraldi (2012) sugerem que as atividades de gestão da Marca Brasil devem envolver a realização de estudos que antecipem possíveis ameaças e oportunidades ao país no que tange ao turismo, abrangendo aspectos políticos, sociais, econômicos e ambientais internos e externos. Assim, questionados a respeito de possíveis ameaças ao fortalecimento do Brasil no cenário turístico internacional causadas pela conjuntura econômica e política negativa no país nos últimos anos, os entrevistados reconhecem que esses fatores realmente não são benéficos para o sucesso de suas atividades. Apesar disso, afirmam que os turistas estrangeiros possuem a capacidade de tratar turismo e aspectos políticos e econômicos como entidades distintas, de modo que problemas na conjuntura nacional não desencorajam a vinda de turistas do exterior. Para reforçar essa ideia, relatam o fato de serem raros os comentários de estrangeiros nas mídias sociais a respeito do atual cenário do país.

Com relação ao cenário econômico brasileiro, foram abordados durante a entrevista aspectos positivos e negativos da desvalorização do real frente ao dólar. Por um lado, a alta do dólar é claramente uma ameaça à economia brasileira e ao trabalho de promoção do Brasil no exterior pela Embratur, já que a realização de qualquer campanha de comunicação fora do país é paga em dólar. Mas por outro lado, essa situação permite que os estrangeiros visitem o Brasil a um preço muito mais competitivo, e assim é esperada e já constatada a vinda de um maior número de turistas estrangeiros ao país.

Outra ameaça ao turismo brasileiro comentada na entrevista é o fortalecimento de países concorrentes, notadamente no que se refere à presença de resorts, aspecto no qual é reconhecido um grande atraso do Brasil frente a outros países que apresentaram forte crescimento nos últimos anos nesse ponto. Por fim, outro obstáculo enfrentado pela Embratur no gerenciamento da Marca Brasil é o fato de que, por estar vinculada ao governo federal, a organização não pode participar da comercialização de produtos turísticos, restringindo-se apenas à atividade de comunicação com o público-alvo. Sobre este ponto, um dos entrevistados explica:

\footnotetext{
Fazemos todo o trabalho de comunicação com os turistas, e quando conseguimos convencê-los a visitar o Brasil, esbarramos na barreira da comercialização dos produtos. Realizamos um trabaIho de relacionamento com o trade turístico, mas não conseguimos fazer uma ponte direta: podemos fomentar a comercialização, mas não comercializar diretamente. Esse de fato é um ponto fraco que temos.
}

Para os gestores da Embratur, a realização dos megaeventos esportivos Copa do Mundo em 2014 e Jogos Olímpicos em 2016 consistiram nas grandes oportunidades desta década para o turismo brasileiro. Diante disso, o foco dos trabalhos da organização não esteve sobre os eventos em si, os quais conseguem se autopromover, mas sobre a divulgação da diversidade turística do país, de modo a mostrar àqueles que vieram ao país para as competições que o Brasil possui muito mais a oferecer do que seus clichês de sol e praia, samba, carnaval, Rio de Janeiro etc. Para essa comunicação, foram utilizadas as diferentes plataformas que a Embratur possui à disposição (tanto online como off-line), envolvendo trade turístico, imprensa e público final. 


\subsection{Ações de Comunicação Digital da Marca Brasil}

Dando agora ênfase à atuação digital da Marca Brasil, inicia-se a discussão afirmando que todas as presenças da marca na internet são realizadas através da iniciativa "Visit Brasil", havendo páginas em mídias sociais e um website que recebe esse nome. Por meio das atividades na internet, a Embratur busca trabalhar a marca junto a três diferentes públicos: trade turístico, imprensa e público final.

Tendo o objetivo de aproveitar as potencialidades da internet para criar e disponibilizar conteúdos para atrair turistas estrangeiros aos destinos turísticos promovidos e suprir as necessidades de informações turísticas desse usuários (Farias et al., 2011; Fernández-Cavia et al., 2014), a Marca Brasil atua com as seguintes presenças digitais:

- Mídias sociais: páginas do Visit Brasil no Facebook, Twitter, Instagram, Flickr e Google Plus. 0 grande foco dessas presenças é o público estrangeiro, embora muitos de seus seguidores sejam brasileiros;

- Canal de vídeos no YouTube: exibe vídeos que exploram diferentes destinos, eventos e experiências turísticas brasileiras;

- Aplicativos de celular: há o jogo Brasil Quest, que tenta mostrar o país de forma lúdica aos estrangeiros, inspirado nos atrativos turísticos das 12 cidades-sede da Copa do Mundo de 2014; e o aplicativo Fellow Trip, que é uma ferramenta de viagem que permite a visualização de dicas turísticas (como restaurantes, hotéis e demais atrações) compartilhadas por outros usuários;

- Portal Visit Brasil: website que agrega informações sobre diversos destinos turísticos brasileiros e suas atrações. Passou por uma grande reestruturação em seu conteúdo, design e organização em abril de 2016, sendo que sua nova versão consiste em um portal menos contemplativo (a versão anterior era bastante visual, com presença marcante de imagens e fotos, porém poucos textos explicativos) e mais informativo (melhorou a quantidade, qualidade e facilidade de acesso das informações turísticas brasileiras). Esse diagnóstico surgiu após a realização de um estudo de usabilidade para entender como os usuários estrangeiros se comportam no website e melhorar a forma de apresentação das informações que os usuários necessitam ao mesmo tempo em que se busca convencê-lo a visitar o país. Assim, seu objetivo central é transmitir e explorar as experiências únicas que podem ser vivenciadas nos destinos turísticos, e, para isso, a Embratur busca manter um contato próximo com os estados brasileiros a fim de obter conteúdos e diferenciais de cada atrativo.

A literatura destaca que a gestão de uma marca-país envolve diferentes setores, organizações e indivíduos (Fetscherin, 2010). Assim, para desempenhar suas atividades de marketing tanto no meio online como no off-line, a Embratur conta com os serviços de sete agências, sendo: três para trabalhos de relações públicas; duas para publicidade, as quais são responsáveis pela criação de campanhas, materiais promocionais e compra de mídia; e duas agências digitais, que trabalham na construção das presenças digitais da organização.

As agências digitais realizam a construção das ferramentas online da Marca Brasil, uma vez que a Embratur, tendo uma equipe de apenas três pessoas, não conseguiria fazer esse trabalho sozinha. Essa pequena equipe é responsável pela interlocução, criação de briefings, filtragem e aprovação de conteúdos.

Mariutti e Giraldi (2011) destacam a importância da padronização e controle de uso da Marca Brasil no ambiente online. Frente a essa necessidade, nada é publicado nas ferramentas online sem a aprovação dos gestores da Embratur, o que busca garantir que todos os conteúdos reforcem a imagem do Brasil que a organização deseja transmitir e para evitar certos estereótipos e clichês que se deseja desestimular. Dentro das agências, não há funcionários exclusivos para trabalhar com a Marca Brasil. A Embratur monta briefings para as agências com aquilo que deseja, e recebe e fornece sugestões. Diante disso, as agências alocam profissionais que serão responsáveis pela execução desse trabalho.

Os entrevistados da Embratur destacam que o grande objetivo da presença digital da Marca Brasil é suprir as necessidades de informação dos potenciais turistas estrangeiros sobre o país, destacando os diferenciais 
de cada destino e as experiências únicas e exclusivas que só existem aqui, conforme explica um dos entrevistados:

\begin{abstract}
Temos o objetivo de suprir informações sobre o Brasil como um destino turístico, além de evidenciar os motivos de escolher o nosso país e não algum outro para visitar. Destacar o que o Brasil tem de diferencial. Por exemplo, sabemos que praia outros países também têm, tão boas quanto as do Brasil, mas buscamos colocar em todas as nossas atividades aquilo que enriquece determinado destino brasileiro, as experiências que só podem ser vivenciadas aqui. $E$ isso envolve a questão das experiências únicas e exclusivas do Brasil.
\end{abstract}

Trabalhos anteriores apontam que abordar de modo persuasivo esses diferenciais de cada país através da internet é um grande desafio para a gestão de marcas-país, uma vez que esse ambiente permite estímulos sensoriais limitados, apenas visuais ou sonoros (Farias et al., 2011; Morrison, 2012). Para transmitir as experiências, eventos e atrações brasileiras únicas através da internet, a Embratur utiliza os diversos recursos interativos e de multimídia propiciados por esse ambiente, além disso se comunica com os usuários de modo mais pessoal e amigável, diferente do tom mais sério e tradicional normalmente utilizado por órgãos governamentais. Em outras palavras, a organização afirma utilizar nesse ambiente conteúdos como vídeos e imagens e textos com um linguajar mais descontraído, convidando os usuários a interagir, participar das discussões e enquetes propostas pela Embratur.

Com relação à origem e seleção dos conteúdos publicados em mídias sociais, os mesmos surgem de diferentes fontes. A equipe da Embratur propõe ideias com base nos relatórios que recebem de seus escritórios no exterior, identificando assuntos e tendências que podem ser oportunidades a serem trabalhadas. São recebidas também informações do trade turístico, que, por saber o que o público final do exterior está procurando naquele momento, fornece sugestões sobre o que é melhor divulgar para determinado país e de que forma a Embratur pode ajudar na ativação dessa demanda. Essas informações são posteriormente comunicadas às agências, que trabalham as ideias e produzem conteúdos com viés comunicativo, publicitário e não-jornalístico. Com base nisso, são colocados no ar os conteúdos que julgam ser mais adequados para cada região do mundo. Além disso, como é comum nas mídias sociais, são aproveitados conteúdos publicados pelos próprios usuários, o que gera grande interação com o público e é bastante apreciado por esses indivíduos. Por meio dessa fonte, são buscados imagens e vídeos que mostram as experiências dos próprios usuários nos destinos, o que traz maior interação, transparência e confiança na comunicação entre Embratur e público final.

Na sequência, serão apresentadas explicações sobre a atuação da Marca Brasil nas principais mídias sociais em que está presente e que foram obtidas nas entrevistas, lembrando que todas elas recebem o nome "Visit Brasil":

- Instagram: uma vez que o grande foco dessa mídia seja o público dos Estados Unidos, as publicações são todas feitas em inglês (embora boa parte de seus seguidores sejam brasileiros). Utiliza belas fotos com cores fortes, mostrando experiências brasileiras (presença de pessoas em muitas das imagens), e não apenas monumentos e paisagens. Busca ser descolado e amigável ao interagir;

- Facebook: com conteúdos em inglês e espanhol, costuma publicar álbuns de fotos, de modo a mostrar maior quantidade de fotos do mesmo destino, abordando seus diferentes aspectos;

- Twitter: trabalhado em inglês e espanhol, publica principalmente imagens e vídeos de pessoas vivenciando diferentes experiências, como esportes, festividades e paisagens;

- Google Plus: é uma mídia social em alta na Europa, sendo também muito importante para melhorar a indexação dos conteúdos da Marca Brasil nos resultados do Google. Publica diferentes tipos de conteúdo (textos grandes e pequenos, imagens, vídeos) e todos costumam ter um bom desempenho, aproveitando o bom momento dessa mídia no exterior.

A maior parte dos acessos dos conteúdos da iniciativa "Visit Brasil" vem da América Latina (destaque para a Argentina), Europa (notadamente Reino Unido e Alemanha) e Estados Unidos. Como dito anteriormente, nas diferentes mídias online são publicados conteúdos gerais para o mundo inteiro e também conteúdos segmentados (específicos para determinado local), já que diferentes públicos reagem de maneiras distintas aos conteúdos publicados. 
Continuando a discussão do parágrafo anterior, os gestores da Embratur reconhecem a importância de utilizar métricas e indicadores a fim de avaliar os resultados de cada presença e o atingimento de seus objetivos. Dessa forma, a organização afirma monitorar com afinco o desempenho de cada atuação Visit Brasil, reunindo-se mensalmente com as agências prestadoras de serviço para discuti-lo.

Para o trabalho em mídias sociais, os principais dados analisados são: número de seguidores, performance de conteúdo, quantidade de acessos, curtidas, comentários e compartilhamentos. Especificamente para o portal, são utilizados a quantidade de acessos, taxa de rejeição (usuários que acessam o website e o abandonam após poucos segundos), tempo de permanência, levantamento das páginas mais visitadas, origem dos acessos, entre outros. A mensuração dos resultados das mídias sociais é considerada mais fácil e ágil, uma vez que as mesmas disponibilizam dados e feedbacks mais rapidamente que permitem saber os conteúdos publicados de maior ou menor sucesso, sendo que o website não possibilita a obtenção de informações dessa natureza. Sobre a mensuração dos resultados das atividades em mídias sociais, os entrevistados explicam:

\footnotetext{
Monitoramos esses números de perto e mensalmente nos reunimos com as agências para discuti-los. Quais foram os melhores e piores conteúdos que publicamos? O que funcionou e o que não funcionou? Analisamos conteúdos do momento a serem trabalhados. E isso é feito de maneira integrada e conjunta entre Embratur e as agências, a fim de garantir a integração e sinergia entre os conteúdos.
}

Seguindo a sugestão de Castro e Giraldi (2012) a respeito da necessidade de monitorar e avaliar as principais oportunidades e ameaças para a Marca Brasil no cenário turístico internacional, a apresentação dos resultados deste artigo se encerrará tratando desse assunto, especificamente sobre a atuação digital da marca.

Uma questão tratada pelos entrevistados como uma espécie de obstáculo às atividades de comunicação digital da Embratur é o excesso de brasileiros seguindo as páginas Visit Brasil nas mídias sociais, os quais corriqueiramente publicam diversas críticas ligadas à segurança, infraestrutura e demais problemas do país, as quais repercutem para o público internacional. Os gestores ressaltam que aqueles que criticam e menosprezam o Brasil na internet são os próprios brasileiros, e não os usuários estrangeiros, sendo esse um problema que a Embratur tem atualmente: boa parte da população local, ao invés de contribuir para a promoção do país no exterior, prefere atrapalhá-la.

Mariutti e Giraldi (2011) afirmam que frente ao número crescente de indivíduos que utilizam a internet para planejar suas viagens, é necessário que seja feito um acompanhamento constante das evoluções em mídias sociais e demais ferramentas da internet, levando em conta tais inovações na definição e adequação das estratégias de construção e gerenciamento da marca-país. Frente a isso, para o futuro a Embratur pretende aproveitar a oportunidade trazida pelo surgimento de novas mídias sociais. Para isso, planeja realizar estudos para entender o funcionamento de cada uma delas, e então definir aonde atuará e de que maneira. Para os gestores, é importante verificar a relevância que cada mídia social tem para a Marca Brasil e para seu público-alvo, se esse público participa dessas mídias e se a Embratur possui conteúdo para trabalhar dentro delas. Além disso, é realizado o monitoramento das atividades de outros países a fim de verificar em quais mídias desenvolvem atividades e de que forma.

\section{CONSIDERAÇÕES FINAIS}

Este artigo se propôs a compreender as estratégias de gestão e comunicação desenvolvidas para a Marca Brasil e sua forma de atuação na internet. Seguindo o método de pesquisa exposto, foi possível descrever a finalidade central da Marca Brasil (promoção do país como um destino turístico internacional), as aplicações da marca e as atividades desenvolvidas visando três diferentes alvos: imprensa, trade turístico e público final.

Frente à forte competição internacional existente no setor de turismo, a Embratur se mostra ciente da necessidade de buscar diferenciação perante os concorrentes, não mais pelas belezas naturais do país, mas principalmente pelas experiências únicas e exclusivas oferecidas pelo Brasil a seus visitantes, explorando sua marcante diversidade, a alegria e receptividade de seu povo e buscando diferentes oportunidades para promover cada um de seus segmentos turísticos. 
Diante da importância de se trabalhar a melhoria da imagem brasileira no exterior a fim de atrair um maior número de turistas, a Embratur deseja promover no cenário internacional a imagem de um país diverso, com cultura marcante e com um povo muito acolhedor e receptivo, aspectos trabalhados em suas campanhas de comunicação.

Ciente do número crescente de pessoas que utilizam a internet para planejar suas viagens, a Embratur trabalha a Marca Brasil por meio de um website de páginas em diversas mídias sociais, sendo que todas essas presenças recebem o nome "Visit Brasil". Em sintonia ao objetivo central da Marca Brasil e às estratégias empregadas para seu atingimento, as presenças digitais da marca têm a finalidade de, selecionando os melhores parceiros e as fontes de informação mais adequadas, criar e disseminar conteúdos que visam suprir as necessidades de informação dos turistas estrangeiros e atraí-los a visitar o país, interagindo com os usuários de modo pessoal e amigável. Ressalta-se também a importância da mensuração dos resultados de cada ação realizada.

Com as informações e discussões apresentadas, pode-se afirmar que o objetivo deste artigo foi atingido. Quanto aos resultados deste estudo, estes podem contribuir para pesquisas acadêmicas que investiguem marca-país (notadamente a Marca Brasil), e de modo mais específico atividades de comunicação digital praticadas em prol de marcas-país.

Os resultados também podem contribuir para organizações envolvidas tanto na gestão da Marca Brasil como em suas aplicações frente ao trade turístico, imprensa e público final, de modo a gerar uma melhor compreensão a respeito das atividades da marca a fim de encontrar e aproveitar oportunidades para potencializar suas aplicações e benefícios. Como sugestão para pesquisas futuras, indica-se a comparação das estratégias e práticas empregadas na gestão e comunicação da Marca Brasil com outras marcas-país, dando ênfase às atuações das mesmas no ambiente da internet.

\section{REFERENCIAS}

Adamson, A. P. (2008). Branddigital: simple ways top brands succeed in the digital world. New York, NY: Palgrave Macmillan.

Anholt, S. (2005). Nation brands index: How does the world see America. Journal of Advertising Research, 45(3), 296-304. https://doi.org/10.1017/S0021849905050336

Bardin, L. (2011). Análise de conteúdo. São Paulo, SP: Edições 70.

Brasil. Perfil de Mercado Estados Unidos 2013. 2014. Disponível em: http://trade.visitbrasil.com. Acesso em: 11 ago. 2018.

Campelo, A., Aitken, R., Thyne, M., \& Gnoth, J. (2014). Sense of place: The importance of destination branding. Journal of Travel Research, 53(2), 154-166. https://doi.org/10.1177/0047287513496474

Carvalho, D. T. et al. Experiência em website de marca-país e a formação da imagem de destino turístico: um estudo na Islândia. Revista Brasileira de Pesquisa em Turismo, v. 10, n. 1, p. 108-128, 2016. https://doi.org/10.7784/rbtur.v10i1.1019

Castro, M. C., \& Giraldi, J. M. E. (2012). Processo de desenvolvimento e gestão de marca-país: um estudo sobre a marca Brasil. Revista Turismo Visão e Ação, 14(2), 164-183.

Chen, C. F., \& Tsai, D. C. (2007). How destination image and evaluative factors affect behavorial intentions? Tourism Management, 28(4), 1115-1122. https://doi.org/10.1016/j.tourman.2006.07.007

Diamantopoulos, A., Schlegelmilch, B., \& Palihawadana, D. (2011).The relationship between country-of-origin image and brand image as drivers of purchase intentions: A test of alternative perspectives. International Marketing Review, 28(5), 508-524. https://doi.org/10.1108/02651331111167624

Fan, Y. (2006). Branding the nation: What is being branded? Journal of Vacation Marketing, 12(1), 5-14. https://doi.org/10.1177/1356766706056633

Fan, Y. (2010). Branding the nation: Towards a better understanding. Place Branding and Public Diplomacy, 6(2), 97-103. https://doi.org/10.1177/1356766706056633

Farias, S. A., Aguiar, E. C., Kovacs, M. H., \& Andrade, F. G. (2011). Imagen de los destinos turísticos en los portales gubernamentales: Análisis de tres localidades brasileñas. Estudios y Perspectivas en Turismo, 
20(6). Disponivel em: $\quad$ http://www.scielo.org.ar/scielo.php?script=sci arttext\&pid=S185117322011000600007. Acesso em: 20 ago. 2018.

Fernández-Cavia, J., Rovira, C., Díaz-Luque, P., \& Cavaller, V. (2014). Web Quality Index (WQI) for official tourist destination websites: Proposal for an assessment system. Tourism Management Perspectives, 9, 513. https://doi.org/10.1016/i.tmp.2013.10.003

Fetscherin, M. (2010). The determinants and measurement of a country brand: The country brand strength index. International Marketing Review, 27(4), 466-479. https://doi.org/10.1108/02651331011058617

Florek, M. (2005). The country brand as a new challenge for Poland. Place Branding, 1(2), 205-214. https://doi.org/10.1057/palgrave.pb.5990021

Hair, J. F., Jr., Celsi, M. W., Ortinau, D. J., \& Bush, R. P. (2014). Fundamentos de pesquisa de marketing (3a ed.). Porto Alegre, RS: McGraw Hill.

Hakala, U., \& Lemmetyinen, A. (2011). Co-creating a nation brand "bottom-up". Tourism Review, 66(3), 1424. https://doi.org/10.1108/16605371111175294

Hakala, U., Lemmetyinen, A., \& Kantola, S. P. (2013). Country image as a nation-branding tool. Marketing Intelligence \& Planning, 31(5), 538-556. https://doi.org/10.1108/MIP-04-2013-0060

Herstein, R. (2011).Thin line between country, city, and region branding. Journal of Vacation Marketing, 18(2), 147-155. https://doi.org/10.1177/1356766711435976

Hynes, N., Caemmerer, B., Martin, E., \& Masters, E. (2014). Use, abuse or contribute! A framework for classifying how companies engage with country image. International Marketing Review, 31(1), 79-97. https://doi.org/10.1108/IMR-12-2012-0206

Khauaja, D. M. R., \& Hemzo, M. A. (2007). Marca Brasil: Ficção ou realidade? Uma análise das iniciativas da APEX-Brasil para a construção da marca Brasil. INTERNEXT: Revista Eletrônica de Negócios Internacionais da ESPM, 2(1), 75-96.

Kotler, P., \& Gertner, D. (2004). 0 estratégico marketing de lugares. Dossiê HSM Management, 44, 62-93.

Malhotra, N. K. (2012). Pesquisa de marketing: uma orientação aplicada. 6 ed. Porto Alegre: Bookman.

Mariutti, F. G., \& Giraldi, J. M. E. (2011). Fundamentos da Marca Brasil: Uma análise da comunicação virtual em websites de agência de turismo. Caderno Virtual de Turismo, 11(1), 60-77.

Ministério do Turismo. (2009). Plano Aquarela 2020: Marketing turístico internacional do Brasil. Disponivel em: http://www.embratur.gov.br/lai_embratur_secom/export/sites/lai/galerias/download/Plano_Aquarela 2020.pdf. Acesso em: 15 ago. 2018.

Morrison, A. M. (2012). Marketing de hospitalidade e turismo. São Paulo, SP: Cengage Learning.

Nadeau, J., Heslop, L., O'Reilly, N., \& Luk, P. (2008). Destination in a country image context. Annals of Tourism Research, 35(1), 84-106. https://doi.org/10.1016/j.annals.2007.06.012

Nebenzahl, I. D. (2007, julho). National image and competitive advantage. Resumos do Simpósio Internacional de Administração, 2; Congresso de Administração da ESPM, 4, São Paulo, SP. Disponivel em: http://www2.espm.br/sites/default/files/pagina/palestra_prof_nebenzahl_25jul2007.pdf

Organização Mundial Do Turismo (OMT) (2017). World Tourism Barometer. 2017 International Tourism Results: the highest in seven year. Disponivel em: http://media.unwto.org/press-release/2018-01-15/2017international-tourism-results-highest-seven-years

Raupp, F. M., Beuren, I. M. (2003). Metodologia de pesquisa aplicável às ciências sociais. In: Como elaborar trabalhos monográficos em contabilidade: teoria e prática. Beuren, I. M. (Org). São Paulo: Atlas.

Rowles, D. (2014). Digital branding: A complete step-by-step guide to strategy, tactics and measurement. London, United Kingdom: Kogan Page.

Stock, F. (2009). Identity, image and brand: A conceptual framework. Place Branding and Public Diplomacy, 5(2), 118-125. https://doi.org/10.1057/pb.2009.2

The World Bank. Perspectivas Econômicas Globais. Disponivel em: http://www.worldbank.org/pt/publication/global-economic-prospects.

WTTC - World Travel and Tourism Council. Disponivel em: www.wttc.org/ 


\section{Informações dos autores}

\section{Flávio Notomi Kanazawa}

Mestre em Administração de Organizações pela FEA-RP/USP.

Ele contribuiu para a coleta e análise dos resultados e para a redação do manuscrito.

E-mail: flavio.nk@gmail.com

ORCID: orcid.org/0000-0001-9412-8360

\section{Janaina de Moura Engracia Giraldi}

(Autora Correspondente)

Professor Associado a Universidade de São Paulo, São Paulo, SP, Brasil.

Ela concebeu a ideia apresentada e contribuiu para a concepção e implementação da pesquisa. E-mail: igiraldi@usp.br

ORCID: orcid.org/0000-0003-3086-7134

\section{Jorge Henrique Caldeira de Oliveira}

Professor Associado a Universidade de São Paulo, São Paulo, SP, Brasil.

Ele contribuiu para a análise dos resultados e para a redação do manuscrito.

E-mail: jorgecaldeira@usp.br

ORCID: orcid.org/0000-0003-3036-9733 